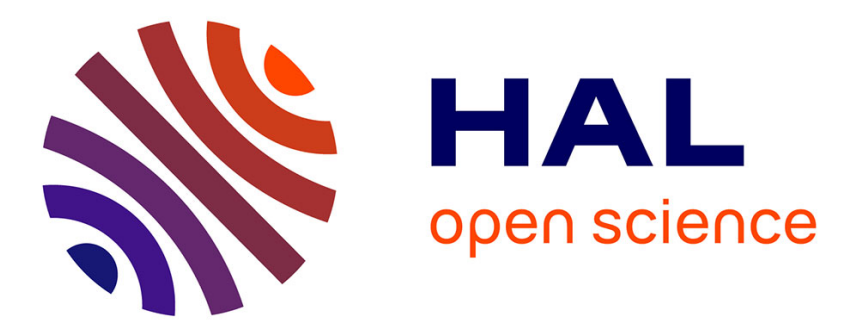

\title{
Relevance of impedance spectroscopy for the monitoring of implant-induced fibrosis: A preliminary study
}

Noëlle Lewis, Cyril Lahuec, S Renaud, Eric Mcadams, Paco Bogonez-Franco, Claire Lethias, Sabrina Kellouche, F Carreiras, Andrea Pinna, Aymeric Histace, et al.

\section{To cite this version:}

Noëlle Lewis, Cyril Lahuec, S Renaud, Eric Mcadams, Paco Bogonez-Franco, et al.. Relevance of impedance spectroscopy for the monitoring of implant-induced fibrosis: A preliminary study. BIOCAS: Biomedical Circuits and Systems, Oct 2015, Atlanta, United States. 10.1109/BioCAS.2015.7348399 . hal-01246840

\section{HAL Id: hal-01246840 \\ https://hal.science/hal-01246840}

Submitted on 19 Dec 2015

HAL is a multi-disciplinary open access archive for the deposit and dissemination of scientific research documents, whether they are published or not. The documents may come from teaching and research institutions in France or abroad, or from public or private research centers.
L'archive ouverte pluridisciplinaire HAL, est destinée au dépôt et à la diffusion de documents scientifiques de niveau recherche, publiés ou non, émanant des établissements d'enseignement et de recherche français ou étrangers, des laboratoires publics ou privés. 


\section{Relevance of impedance spectroscopy for the monitoring of implant-induced fibrosis: a preliminary study}

\author{
N. Lewis ${ }^{1}$, C. Lahuec ${ }^{2}$, S. Renaud ${ }^{1}$, E. McAdams ${ }^{3}, \mathrm{P}$. \\ Bogonez-Franco $^{3}$, C. Lethias ${ }^{4}$, S. Kellouche ${ }^{5}$, F. \\ Carreiras $^{5}$, A. Pinna ${ }^{8}$, A. Histace 9 , M. Boissiere ${ }^{5}$, E. \\ Pauthe $^{5}$, I. Lagroye ${ }^{1}$, F. Soulier ${ }^{6}$, S. Bernard ${ }^{6}$, S. \\ Binczak $^{7}$, B. Granado ${ }^{8}$, P. Garda ${ }^{8}$, M. Terosiet ${ }^{9}$, A. \\ Goguin $^{9}$ and O. Romain ${ }^{9}$
}

1. IMS, UMR5218 Univ. de Bordeaux, Bordeaux, France 2. TELECOM Bretagne, Brest, France

\begin{abstract}
This paper focuses on the study of fibrosis induced by an implanted medical device and explores the possibility of characterizing this process by in situ measurement of electrical impedance. The approach combines concurrent electrical and biological characterizations of fibrotic tissue, applied to electrodes implanted in an animal model. The methodology used is described. Initial results evidence the strong correlation between fibrotic tissue and electrical parameters. Identification of such electrical parameters will enable the establishment of a reliable monitoring method.
\end{abstract}

Keywords-Fibrosis, Electronic Implant, Impedance spectroscopy, Embedded System, Medical Devices

\section{INTRODUCTION}

Innovations in integrated circuit technologies have spurred a revolution in in vivo healthcare monitoring, thereby catalyzing a significant growth in implantable medical devices. A variety of diseases and disabilities can now be addressed using medical implants [1] and prosthetics [2]. Active implants, such as pacemakers [3-4] and neurostimulators [5], act by electrical stimulation of targeted tissues The degradation of the electrode-living tissue interface over time has a major impact on the reliability and functionality of a wide range of implanted devices. Among the dysfunctions identified by pacemaker manufacturers, for instance, fibrosis at the myocardial tissueelectrode interface is considered a source of pacing problems as critical as battery depletion

When a device is implanted, the foreign body reaction occurs which is characterised by the infiltration of inflammatory cells to the area of the implant, and this persists until the material becomes encapsulated in a dense layer of fibrotic connective tissue. The efficiency of the device, once shielded by tissue, can be severely compromised. The standard method for determining the degree of tissue reaction is via
3. INL, UMR5270, Univ. de Lyon 1, Lyon, France

4. IBCP, FR3302, Univ. de Lyon 1, Lyon, France

5. ERRMECe, EA1391, Univ. de Cergy-Pontoise, CergyPontoise, France

6. LIRMM, UMR5506, Univ. de Montpellier, Montpellier, France

7. LE2I, UMR6306, Univ. de Bourgogne, Dijon, France 8. LIP6, Université Paris 6, Paris, France

9. ETIS, UMR8051, Univ. Cergy-Pontoise, CergyPontoise, France

histological examination. This approach enables the visualization of specific proteins but does not enable one to follow the tissue reaction time course in a living animal [6]. To assess the contribution of local tissue response to implant failure, there is therefore an urgent need to develop tools to non-invasively determine the extent, morphology and composition of local tissue response surrounding implanted devices.

Characterisation of implanted electrodes and the surrounding tissues using electrical impedance monitoring can be found in the literature. Stein et al. pioneered in vivo study on recording electrodes on mammalian nerves (cuff electrodes) [7] using impedance spectroscopy. The low frequency impedance $(10 \mathrm{~Hz})$ reflected the capacitive component of the interface and the high frequency impedance $(10 \mathrm{kHz})$ reflected the tissue resistance, based on the authors' simplified and linear equivalent circuit model. They observed that the apparent tissue resistivity increased for several weeks after implantation, which was attributed to the replacement of fluid within the cuff by connective tissue. The study of Grill et al. used the 4-point technique on subcutaneous electrodes arrays to measure more specifically the local tissue impedance and eliminate the interface impedance components [9], In vivo measurements were performed with a biphasic current pulse which provided a measure of DC resistivity in steady-state regime. This study was mainly focused on the tissue resistivity with time following implantation and a high resistivity was attributed to the growth of a dense tissue. Mc Connell et al. perform twoelectrode impedance spectroscopy measurements and used the well-known Cole model. They proposed a quantitative and exhaustive correlation analysis between biological and electrical markers of brain implanted electrodes [6]. Although the specificity of brain tissue gives rise to a tissue reaction known as gliosis instead of fibrosis, this methodology is similar to our approach. 
This paper investigates the characterization of fibrosis based on electrical makers. To do so, the formation and evolution of fibrosis around implanted electrodes based on biomarkers typical of this type of tissue is also studied. Variations in the electrode impedance are observed concurrently, at different time intervals. Three mini-pigs were implanted with cuff electrodes on both carotid arteries. Electrode-tissue impedances were characterized over a period of 37 days. Histological and biological analyses were conducted, once the pigs were ethically sacrificed, on the electrodes and surrounding tissues. Then the concomitant evolution of fibrosis biological markers and impedance parameters over the period was studied.

The remainder of this paper is organized as follows. Section II describes fibrosis as well as typical biomarkers used. Section III deals with impedance spectroscopy. Section IV describes the methodology used in our experiments. Section V presents the biomarkers. Section VI provides the results obtained. Finally, Section VII concludes the paper.

\section{FIBROSIS}

Production of fibrotic tissue is a reparative process beginning once an in vivo device has been implanted into the body. In the first days after the device is implanted, an innate inflammatory reaction is induced, characterized by diffusion of molecules called cytokines. These molecules interfere with the nearby environment by activating a cellular proliferation phenomenon jointly with the proliferation of cells with repairing capabilities called myofibroblasts. The proliferation of myofibroblasts is strongly related to the production of an extracellular matrix that can be indirectly emphasized by visualization of dedicated proteins: fibronectin and collagenous fibers. Fibronectin aggregates the myofibroblasts through the activation of a migration step. In parallel, the collagen induces a rigidity in the new born tissue. In the normal healing process, the myofibroblasts slowly vanish once the inflammatory phenomenon stops. The tissue volume reduces and returns to close to the original structure. The fibrosis phenomenon differs from healing since the presence of activated cells (expressing $\alpha$-Smooth Muscle Actin, $\alpha$-SMA) is maintained over a longer duration implying a continuous accumulation of extracellular matrix (ECM). This "fibrotic" tissue is thus essentially made of threads of collagen fibrils and of myofibroblasts that encapsulate the foreign device, so that it can no longer be "seen" by the body. In the case of a chemically-stable and uncorrupted material, the thickness of the capsule stabilizes after a phase of growth [6].

\section{IMPEDANCE SPECTROSCOPY}

When characterizing the multi-frequency impedance of an implanted electrode interface, two components can generally be identified: the electrode-tissue interface impedance dominates at low frequencies and the tissue impedance dominates at high frequencies. In a Nyquist diagram, we generally find two "depressed" semi-circular arcs whose centres lie below the real axis and whose high and low frequency intercepts with the real axis are at angles $\phi \neq 90^{\circ}$ [9] (Fig.1).

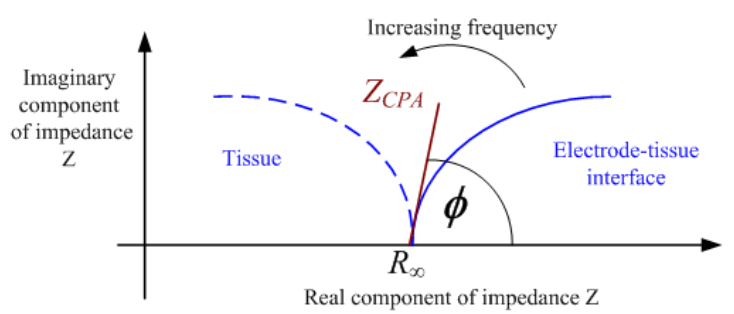

Fig. 1: Typically observed overall impedance locus.

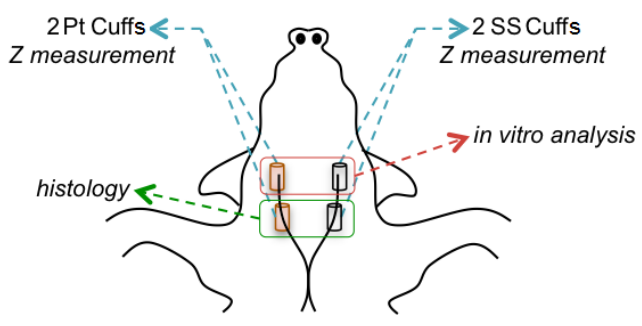

Fig. 2: Implementation sites of cuffs and measurements.

Cole (1940) proposed the now much used empirical equation which describes reasonably well such "depressed" tissue impedance loci:

$\mathrm{Z}=\mathrm{R}_{\infty}+\left(\mathrm{R}_{0}-\mathrm{R}_{\infty}\right) /\left[1+(\mathrm{j} \omega \tau)^{\alpha}\right]$

$\tau$ is a time constant equal to $1 / 2 \pi \mathrm{f}_{\mathrm{c}}$ and $\alpha$ is a fractional power dependency related to the depression angle such that $=\alpha \pi / 2$, $\alpha$ is a constant such that $0.5<\alpha<1$. A simple interpretation of the above equation is in terms of a circuit where a resistance $R_{\infty}$ is in series with the parallel combination of a resistance $\Delta \mathrm{R}$, equal to $R_{0}-R_{\infty}$, and a Constant Phase Angle impedance $\mathrm{Z}_{\mathrm{CPA}} . \mathrm{Z}_{\mathrm{CPA}}$ can be derived from the Cole equation and has the form:

$$
Z_{C P A}=1 / Q(\mathrm{j} \omega)^{\alpha},
$$

where $Q$ is a measure of the magnitude of the pseudo capacitance and has units of $s^{\alpha} / \Omega$ or Fs ${ }^{\alpha-1}$ [9]. The low frequency intercept of the electrode interface arc is denoted $R_{\infty}$ on Fig. 1 and corresponds to the tissue, or extracellular fluid, resistance.

\section{IDENTIFYING FIBROSIS}

An experimental approach, based on repeated in vivo impedance measurements over time, along with periodic biological characterizations, was adopted to identify physical and biological key influences in the formation and development of fibrosis. Three mini-pigs were implanted with cuff electrodes, on both carotid arteries, under anesthesia, Fig. 2. This implementation site was chosen for its practicality. Electrode impedances were characterized every three to five days over a period of 37 days. Histological and biological analyses were conducted on the electrodes and surrounding tissues at day 1 (D1) for pig \#0, 15 (D15) for pig \#1 and day 37 (D37) for pig \#2 after the pigs were ethically sacrificed. The time scale was chosen to observe different phases of fibrosis on the electrodes. The time periods between D1 and D15, and between D15 and D37 characterize the inflammation and the chronic impact. 


\section{A. Electrodes}

Platinum (Pt) and Stainless Steel (SS) nerve cuff (NC-5-5-4$100 \mu \mathrm{m}$ and $\mathrm{Pt} / \mathrm{SS}-300 \mathrm{~mm})$ 4-contact electrodes from MicroProbes $^{\mathrm{TM}}$ were chosen for this study. The stranded wires are $300 \mathrm{~mm}$ long. The inner cuff diameter of $5 \mathrm{~mm}$ is welladapted for the mini pig carotids. The four contacts denoted $\mathrm{P}_{1}$ to $\mathrm{P}_{4}$, of the cuff electrodes enabled the measurement of several combinations of 2-point impedances: we chose $Z_{14}$ and $Z_{23}$ (Fig. 3). Measurements were conducted on a total of twelve cuffs implanted on the three pigs.

\section{B. Impedance measurements}

The electrode-tissue impedances were measured using the 2probes sensing method and an E5060B Agilent network analyzer. The network analyzer was calibrated before each impedance measurement. Due to considerable artifacts at frequencies above $100 \mathrm{kHz}$, measurements were restrained to a $5 \mathrm{~Hz}$ to $100 \mathrm{kHz}$ frequency range. Over this frequency range, the semicircular arc due to the tissue resistance is not seen, only its low frequency intercept, $R_{\infty}$ is observed. Therefore, the overall measured impedance was modeled as a simple resistance $R_{\infty}$ in series with $Z_{C P A}$. Parameters $R_{\infty}, Q$ and $\alpha$ were extracted from the gain-phase measurements with a commercial software (ZView ${ }^{\mathrm{TM}}$ ).

\section{Histological ANALYSIS - EVALUATION OF FIBROSIS MARKERS}

This analysis was performed on the tissues associated with the explanted cuffs. Fibrosis intensity was determined by a combination of two analyses described next.

\section{A. Thickness of fibrotic tissue}

Fibrosis intensity was evaluated by measuring thickness of this tissue associated with the cuffs. Explanted tissues were rapidly frozen and cryostat sections stained with toluidine blue, enabling the visualization of cells and extracellular matrix. Microscopic examination was performed with an optical microscope and thickness $t$ was measured using an ocular reticule.

\section{B. Characterization of fibrosis indicators on in vitro fibroblasts cultures}

Immunohistochemistry and specific antibodies were used in order to identify three main fibrosis markers: $\alpha$-SMA, fibronectin and type I collagen.

Explanted cuff-electrodes (with associated tissue or not) were incubated 24 hours in cell culture medium (DMEMGlutamax with antibiotics). These conditioned media containing fibrosis indicators secreted in vivo were used in fibroblast cells culture and kept in $5 \% \mathrm{CO}_{2}$ in a humidified atmosphere at $37^{\circ} \mathrm{C}$. To ascertain the involvement of soluble factors secreted into the cuff-electrode conditioned media in the effects observed, culture medium which had never been in contact with the cuff electrodes was used as control.
Fibroblasts were cultured on glass coverslips, fixed with $3 \%$ paraformaldehyde in phosphate buffer saline (PBS) and permeabilized with $0.1 \%$ Triton X-100 in PBS. The coverslips were saturated with $0.5 \%$ bovine serum albumine (BSA) in PBS, washed with PBS supplemented with $0.5 \%$ BSA and $0.1 \%$ Tween (rinsing buffer) and incubated with primary antibodies (AbCAM) for two hours at room temperature. They were then washed in rinsing buffer and incubated with secondary antibodies conjugated with Alexa Fluor 555 (Life Technologies) for one hour. Finally, nuclei were stained with 4',6'-diamidino-2-phénylindole (DAPI). Coverslips were mounted in Prolong Gold antifade reagent (Invitrogen) and examined with laser scanning confocal microscopy (LSM710, Zeiss). Controls in which primary antibodies were replaced with PBS were negative.

Figure 4 illustrates the detection of fibrosis biomarkers, namely thickness of fibrotic tissue (Fig. 4 (a)) and $\alpha-S M A$ expression in fibroblast cultures conditioned by fibrotic tissue originally surrounding the electrodes (Fig. 4 (b)). Presence of fibrosis indicators was denoted as follows: " 0 " absence; " 1 " organized marker(s) "2" marker(s) in fibrillar organization and "3" marker(s) in intense fibrillar organization. Presence of cell $\alpha$-SMA, was denoted similarily ("0" absence to " 3 " plentiful).

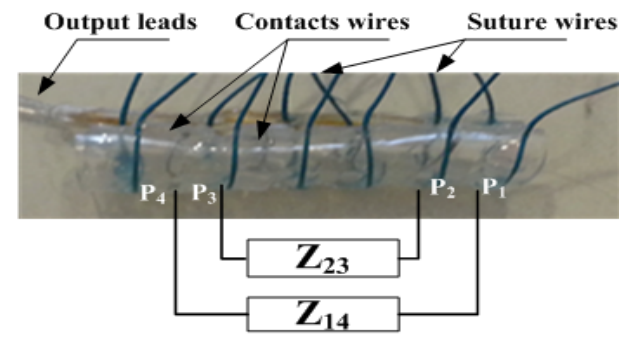

Fig. 3: 4-contact cuff electrode used. Inner diameter $5 \mathrm{~mm}, 100 \mu \mathrm{m}$ contacts, 5 $\mathrm{mm}$ apart.

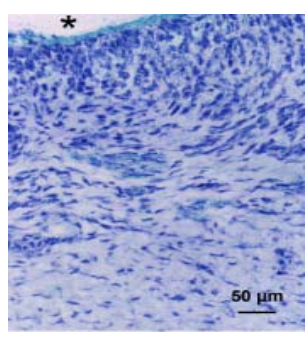

(a)

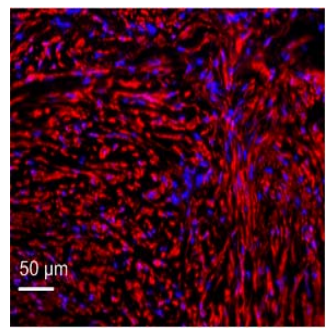

(b)
Fig. 4: Microscopic evaluation of fibrosis intensity. (a) Micrograph of section stained with toluidine blue. * indicates the position of the implanted material. (b) detecting $\alpha$-SMA (red) in vitro (nuclei in blue)

\section{RESULTS : COMPARING BIOMARKERS AND IMPEDANCE}

Figure 5 (a), (b) and (c) show variations over time (from D1 to D37) in $R_{\infty}, Q$, and $\alpha$; these parameters were extracted from $Z_{14}$ and $Z_{23}$ measurements and averaged for each electrode type: six Pt or SS cuffs at D1, four cuffs until D15 and two cuffs until D37 (see section IV-A). 


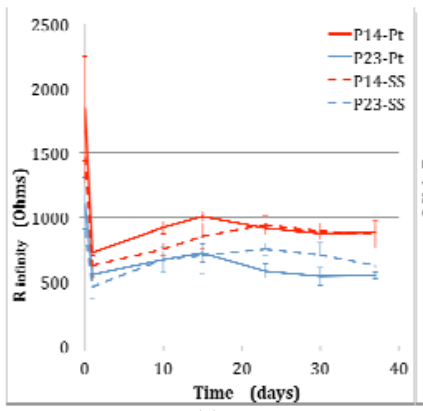

(a)

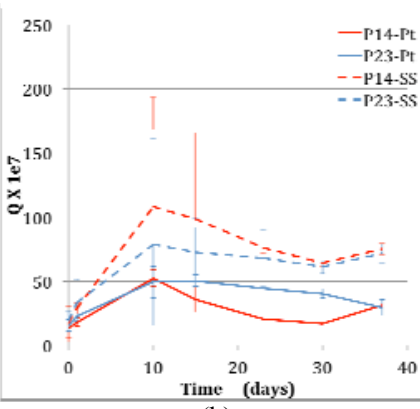

(b)

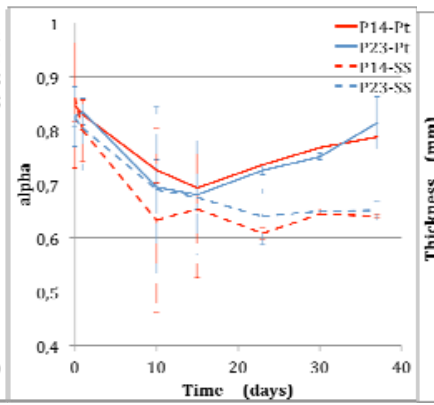

(c)

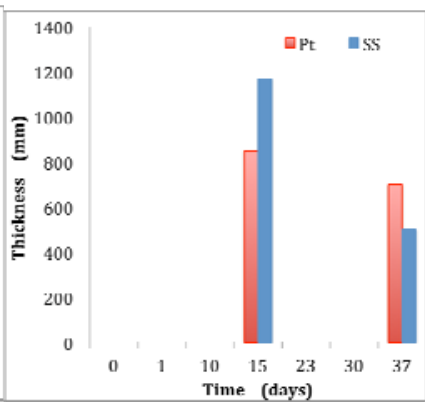

(d)

Fig. 5: In vivo impedance measurements (average values), (a) $R_{\infty}$, (b) $Q$, (c) $\alpha$. (d) Microscopic evaluation of fibrosis intensity: thickness measurements of tissues associated with cuffs

TABLE 1: IN VITRO FIBROSIS MARKERS DETECTION FROM FIBROBLAST CULTURES FOR STAINLESS (SS) AND PLATINUM (PT) ELECTRODES (FROM ABSENCE, '0', TO STRONG DETECTION, "3”).

\begin{tabular}{|l|l|l|l|l|l|}
\hline $\mathrm{SS} / \mathrm{Pt}$ & \multicolumn{2}{l|}{ organization } & \multicolumn{3}{l|}{ Staining } \\
\hline & Fn & Coll & Fn & Coll & $\alpha$ SMA \\
\hline $\mathrm{D} 1$ & $2 / 2$ & $1 / 2$ & $1 / 1$ & $1 / 3$ & $1 / 3$ \\
\hline $\mathrm{D} 15$ & $2 / 2$ & $1 / 2$ & $2 / 2$ & $2 / 2$ & $2 / 1$ \\
\hline $\mathrm{D} 37$ & $2 / 2$ & $0 / 1$ & $2 / 3$ & $1 / 1$ & $0 / 1$ \\
\hline
\end{tabular}

The overall behavior over time of the impedance parameters was reproducible. $R_{\infty}$ dropped rapidly after implantation, then increased over the first two weeks and tended to stabilize until D37, a behavior consistent with the results of resistivity in [8]. $Q$ and $\alpha$ reached their extrema between D10 and D15. $Q_{\max }$ and $\alpha_{\min }$ values present a strong variability between pigs which suggests that the timing and amplitude of fibrosis reaction is subject dependent. $Q$ and $\alpha$ chronograms appear to differ for Pt and SS cuffs. Similarly, the frequency dependence of the tissue resistivity was observed to depend on the type of implant in [8].

Histological analysis (see section V.A.) conducted at D1, D15 and D37 on the three pigs showed that fibrosis tissue thickness was maximum at D15, with a range varying from $850 \mu \mathrm{m}$ to $1200 \mu \mathrm{m}$. At D37 the thickness decreased below $700 \mu \mathrm{m}$. Thickness variation was larger for the SS cuff. Similarly, in vitro fibrosis indicators of staining and organization (see section V.B.) were accentuated at D15 and slightly decreased at D37. Table 1 shows the detection of in vitro fibrosis markers detection from fibroblast cultures. Fibronectin (Fn) is more accentuated in time in terms of expression and organization for Pt cuffs than for SS cuffs. Expression of type I collagen (Coll) shows that the molecule organization is also more pronounced with $\mathrm{Pt}$ than with SS cuffs.

The timing of the changes in electrical parameters appears to be consistent with the timing of the events involved in the fibrotic process. While $R_{\infty}$ and $Q$ appear to be correlated with the fibrotic capsule thickness, $Q$ and $\alpha$ could give quantitative information on the molecular organization of the fibrotic tissue.

\section{CONCLUSION}

This paper involves the study of fibrosis induced by an implanted medical device. The empirical approach combines electrical and biological characterizations of fibrotic tissue, applied to electrodes implanted in an animal model. A comparative study of electrical and biological parameters collected as a function of time shows a correlation between electrical markers of fibrosis development and biological markers. Based on these preliminary results, new experiments will be performed. We expect this technique to become an efficient tool for real-time monitoring of fibrosis induced by implants.

\section{ACKNOWLEDGMENT}

The authors thank C. Kang and M. Bonneau from XPMED St Germain en Laye, France, for animals preparation and surgery.

This work is supported by the DEFI-SENS program of the French National Research Agency (CNRS).

\section{REFERENCES}

[1] J. Mazeyrat, et al., « Wireless Communicative Stent for Follow-Up of Abdominal Aortic Aneurysm", 2006 IEEE Biomedical Circuits \& Systems Conference, pp. 237-240, Nov 29 -Dec 1, 2006.

[2] C. Lahuec, et al.,"A self-powered telemetry system to estimate the postoperative instability of a knee implant". IEEE Transactions on Biomedical Engineering, Vol. 58, n 3, pp 822-825, March 2011.

[3] M. A. Wood and K. A. Ellenbogen, "Cardiac Pacemakers From the Patient's Perspective", Circulation, 2002, Vol 105, pp 2136-2138.

[4] L. R. Hochberg, et al, "Visual Prosthesis," Proceedings of the IEEE , Vol.96, no.7, pp 1076,1084, July 2008

[5] D. Fischell, R. Fischell and A. Upton, "Implantable neurostimulator having a data communication link", US/200220002390, US Patent App. 09/932,178, 2002.

[6] G. C. McConnell, R J Butera and R V Bellamkonda, "Bioimpedance modeling to monitor astrocytic response to chronically implanted electrodes", J. Neural Eng. 6, 2009.

[7] R. B. Stein, D. Charles, T. Gordon, J.-A. Hoffer, J. Jhamandas, Impedance Properties of Metal Electrodes for Chronic Recording from Mammalian Nerves, IEEE Transactions on BioMedical Engineering, Vol. 25, No. 6, Nov 1978.

[8] W. M. Grill, J. T. Mortimer, Electrical Properties of Implant Encapsulation Tissue, Annals of Biomedical Engineering, Vol. 22, pp. 23-33, 1994.

[9] E. McAdams, "BioElectrodes", Encyclopedia of Medical Devices and Instrumentation, pp 120-166, Second Edition, edited by J. Webster. 2006 John Wiley and Son 